\title{
PALEOLANDSCAPE RECONSTRUCTION BASED \\ ON THE STUDY OF A BURIED SOIL OF THE MIDDLE AGES \\ IN THE FOREST-STEPPE AREA OF THE EAST EUROPEAN PLAIN
}

DOI: http://dx.doi.org/10.18509/GBP.2020.26

UDC: 903.5:551.8]:551.583.7(470+571)

\author{
Tatiana Puzanova ${ }^{1}$ \\ Fatima Kurbanova ${ }^{2}$ \\ Gennady Starodubtsev ${ }^{3}$ \\ Olga Rudenko ${ }^{4}$ \\ Olga Khokhlova 5 \\ ${ }^{1}$ Faculty of Geography, Lomonosov Moscow State University, Russian Federation \\ ${ }^{2}$ Faculty of Soil Science, Lomonosov Moscow State University, Russian Federation \\ ${ }^{3}$ Kursk state regional museum of archaeology, Russian Federation \\ ${ }^{4}$ Orel State University, Russian Federation \\ ${ }^{5}$ Institute of Physical, Chemical and Biological Problems in Soil Science, Russian Academy of \\ Sciences, Russian Federation
}

\begin{abstract}
The medieval climatic optimum and the subsequent cooling of the climate over a short time interval had a significant impact on natural conditions and the migration of the population of the steppes of Eurasia. To identify the dynamics of forest-steppe landscapes in the Middle Ages, buried soils under mounds in the central part of the forest-steppe zone of the East European Plain were studied. Soils buried under mounds contain unique information about the paleoclimatic conditions that existed in the study area in the XIXII centuries. The reconstruction of the paleo-environment is based on the analysis of paleosols and palynological materials obtained from the upper horizons of buried soils under the mounds. With the medieval climatic optimum of the Holocene, forests penetrated the steppe territories and humid pedogenesis dominated; while during aridization, of steppe features of soil formation appeared.
\end{abstract}

Keywords: buried soils, archaeological sites, Holocene, palynology, paleoclimate

\section{INTRODUCTION}

Soils buried under burial mounds are one of the natural archives that can store information about the natural conditions of the past. Due to isolation from external environmental factors, a kind of "conservation" occurs. As a result, in the profile of the buried soil there are signs that retain information about the features of the natural environment at the time of its burial.

A comparative analysis of the properties of soils buried under archaeological sites of different ages allows us to examine in detail the changes in the natural environment and its individual components over time. In addition, soils are able to store a whole range of additional features of non-pedogenic origin, which can be used for a more detailed reconstruction of the natural environment. Thus, spores and pollen of plants, phytoliths, faunal remains, etc., are preserved in the soil profile. Therefore, the soil profile can be considered as a kind of data archive containing unique information about the features of past natural settings. 
Until now, the issues of climate change during the small climatic optimum and the small ice age are rather poorly studied within the territory of the Central forest-steppe. According to accepted chronology, a small climatic optimum corresponds to the VIIIXIII centuries AD. This period characterized by a sharp warming of the climate for most of the northern hemisphere. The peak of warming was noted for the chrono-interval of the X-XI centuries AD. An analysis of Russian chronicles indicates that the climate of the European part of Russia changed significantly during this time [1]. In some periods, during extreme natural phenomena such as droughts, climate change led not only to famine of the population, but also to social upheaval. According to the chronicles, the climate of ancient Russia during the period of a small climatic optimum in the X and XI centuries was warm and was characterized by frequent droughts. From the 12th century Russian chronicles indicate an increase in intra-seasonal and extreme climate variability: long cold winters, long rains in the summer seasons, early freezing in late summer - early fall. All these weather phenomena were the harbingers of the small ice age. The first third of the 12th century is considered to be the border of the transition to small ice age. At this time, the number of floods and summer frosts increased, which led to the death of crops and was the cause of hunger, epidemics and population loss [1].

\section{LOCATION}

In 2019, an ancient Russian expedition of the Kursk State Regional Museum of Archeology conducted studies of the Gochevsky archaeological complex located on the right bank of the river Psel near settlement Gochevo, Belovsky district, Kursk region. The area is located within the Central Russian forest-steppe province of the East European Plain.

The natural grass-meadow steppe vegetation was mainly preserved only on the slopes of the balkas. Steppe areas are almost completely plowed up, and the forests are mainly represented by oakery and artificial forest belts (forest cover less than 10\%). The climate is continental. The parent rocks in the study area are Quaternary loess like loams, under which sandy-clay deposits of Paleogene and Neogene occurred. Podzolized, leached, and typical chernozems $(75 \%)$ are predominate in this area; dark-gray forest soils prevail under broad-leaved forests (Fig. 1).

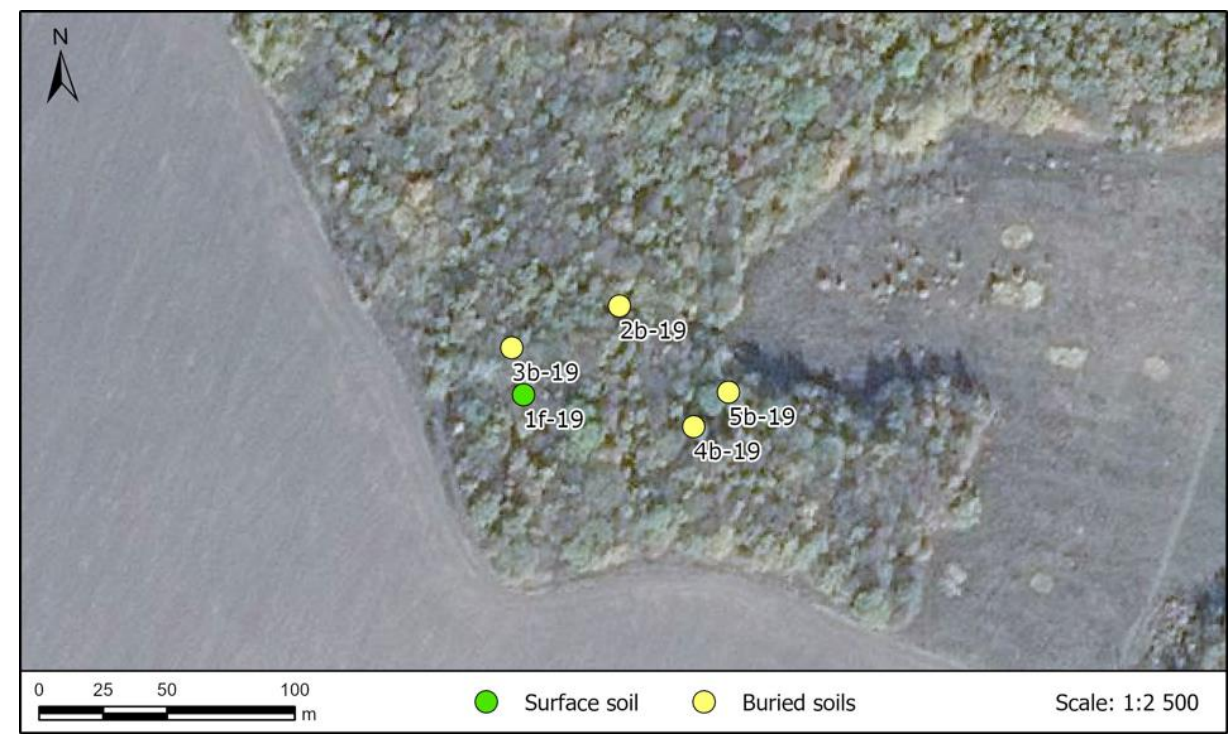

Figure 1. Location of the study area 


\section{METHODS AND AIM OF STUDY}

Archaeological research of the Gochevsky burial ground has been carried out since 1909 . The purpose of archaeological research is to study the evolution and features of the funeral rites of the Old Russian population of the southeast of Russia at the end of the X - XII centuries AD. The main goal of soil and archaeological research conducted in 2019 was to reconstruct successive changes in natural conditions in the medieval era with the use of paleogeographical methods [8].

To reconstruct the vegetation cover palynological analysis was performed in the upper horizons of the surface soil and in 5 samples of buried soils. Since the burial mounds had a small thickness, and buried soils could partially be involved in the modern process of soil formation, samples were also taken from the lower part of the mound to clarify the boundaries of the paleosol. The taxonomic identification of microfossils was carried out using published keys and atlases [2], [3], [4], as well as electronic databases of photo pollen and non-pollen palynomorphs (NPP database, Paldat, European pollen database, etc.) with a use of a Motic-B1- microscope 220A at magnification $\times 400$. Non-pollen palynomorphs were additionally studied: organic residues of aquatic microorganisms, spores of coprotrophic and parasitic fungi on decaying plants and roots of trees, and difficult and indefinable spores of fungi are combined into this group. In each sample, the number of coal microparticles, which are among the effective eco-indicators, was also calculated. To calculate percentage ratios and build spore-pollen diagrams, the Tilia / TiliaGraph / TGView software package [5], [6] was used. In the percentage calculation, the sum of the pollen of trees and shrubs (AR) and herbaceous plants (NAP) - AP + NAP is taken as $100 \%$. The percentage of all taxa is calculated from this amount.

\section{RESULTS}

The Gochevsky burial mound is one of the largest identified and preserved monument to nowadays in modern Eastern Europe. The investigated burial ground was built at the turn of the X-XI - XII centuries. The entire burial ground consisted of three thousand burial mounds, however, after intensive plowing, only areas under the forest were preserved. In total, about 800 mounds were preserved in a small area currently occupied by deciduous forest.

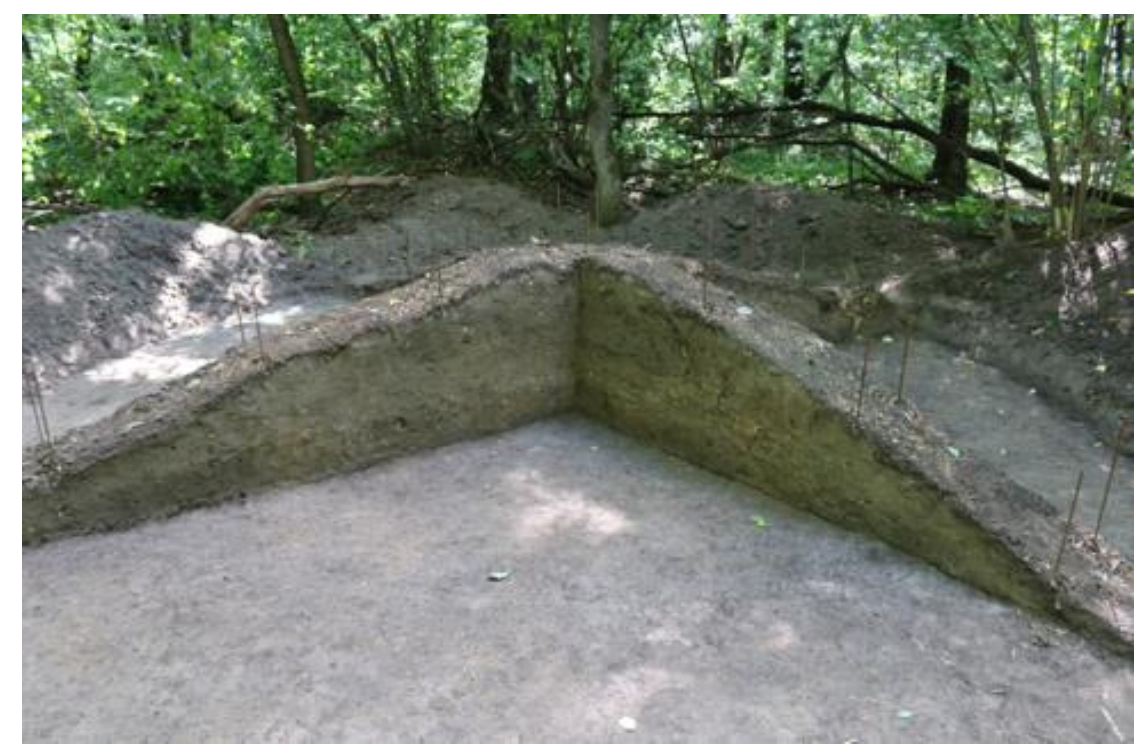

Figure 2. Excavations of the mound № 121 
The height of the mounds is about $40-50 \mathrm{~cm}$, and the diameter is about 3-4 meters. The morphogenetic properties of soils buried under 6 mounds, as well as the soil cover of the surrounding area, were investigated within the burial complex. To carry out the natural reconstruction of medieval landscapes, we used the method of buried and daytime chronosequences (Fig. 2).

All mounds were built at one time, the difference between them was 25-50 years. Despite such a short period of time between the construction of burial mounds, during morphological studies of paleosols, differences in medieval soils caused by changes in the degree of climate humidity were noted (Fig. 3).
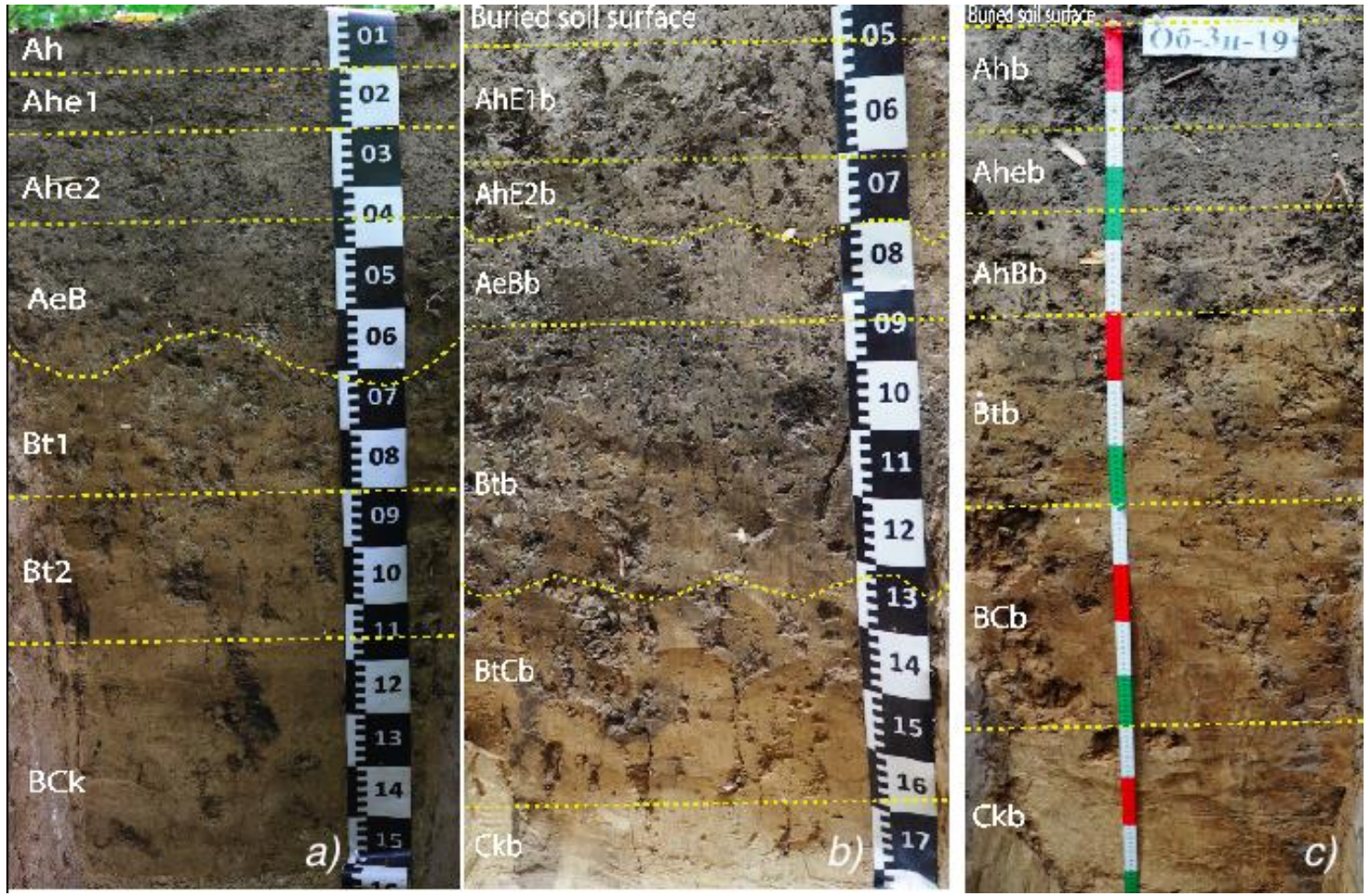

Figure 3. Surface and buried soils of Gochevsky burial ground. a) Surface soil b) Soil buried in the second half of XIth century (burial mound №86), c) Soil buried in the second quarter/middle of XIth century (burial mound №121)

The medieval climatic optimum (about 1100 years ago) was characterized not only by higher average annual temperature characteristics compared to modern times, which were $10^{\circ} \mathrm{C}$ higher, but also by increased humidity. During this period, the average annual rainfall was $25-50 \mathrm{~mm}$ higher [7]. The climatic optimum, which lasted until the beginning of the XIII century, was divided by a phase of strong cooling in the XI century, during which the average annual temperatures were $0.5^{\circ} \mathrm{C}$ lower than the modern ones, and the rainfall was $25 \mathrm{~mm}$ lower (Fig. 4).

Palynological studies have revealed that the sample of the surface soil is most saturated with pollen. The composition of the surface sample of the surface soil (1f-19) characterizes modern vegetation - a broad-leaved forest of Quercus robur oak and Acer maple with undergrowth hazel Corylus and Euonymus verrucosus. However, European pine pollen Pinus silvestris predominant in palynospectrum, which accounts for more than $50 \%$ of $75.9 \%$ of pollen among woody plants. Such a feature of the spectrum is 
typical for the northern forest-steppe regions and is explained by the high pollen productivity of the pine and its high transportability by the wind (Fig. 5).

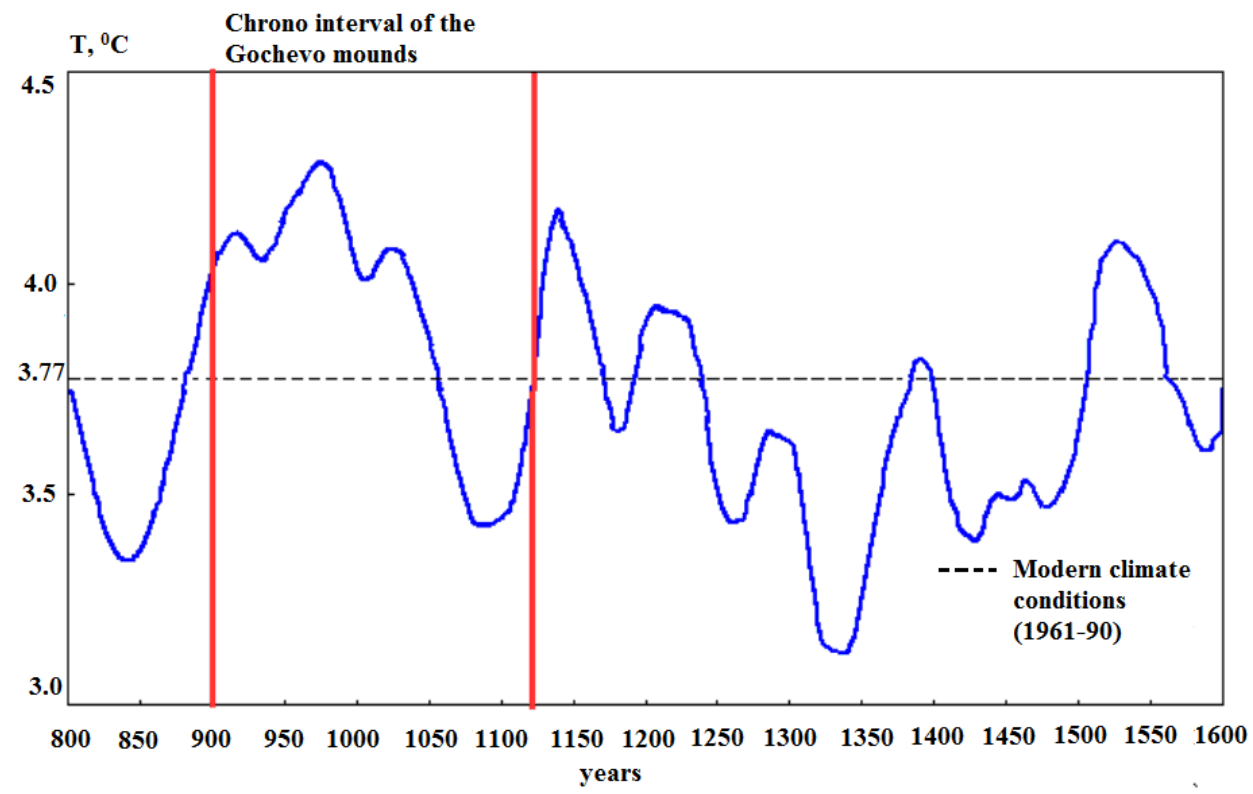

Figure 4. The average annual air temperature in the centre of the East European Plain in the IX-XVII centuries (generalized data).

The pollen group of non-woody plants $(24.1 \%$ in total $)$ is dominated by pollen of Asteraceae, Mara, cereals and sedges, which is consistent with the geobotanical description of the territory (Chenopodium album, Carex pilosa, etc.). The group of synanthropic plants in the spectrum is represented by pollen of Urticaceae, Plantago stepposa, Artemisia cf. absinthium, chicory vulgaris, Chenopodium album, etc. The spores of the spectrum are dominated by spores of sphagnum mosses and the lycopodium of the annual Lycopodium annotinum. In general, the pollen composition bears sign of xerophytization of grassy vegetation.

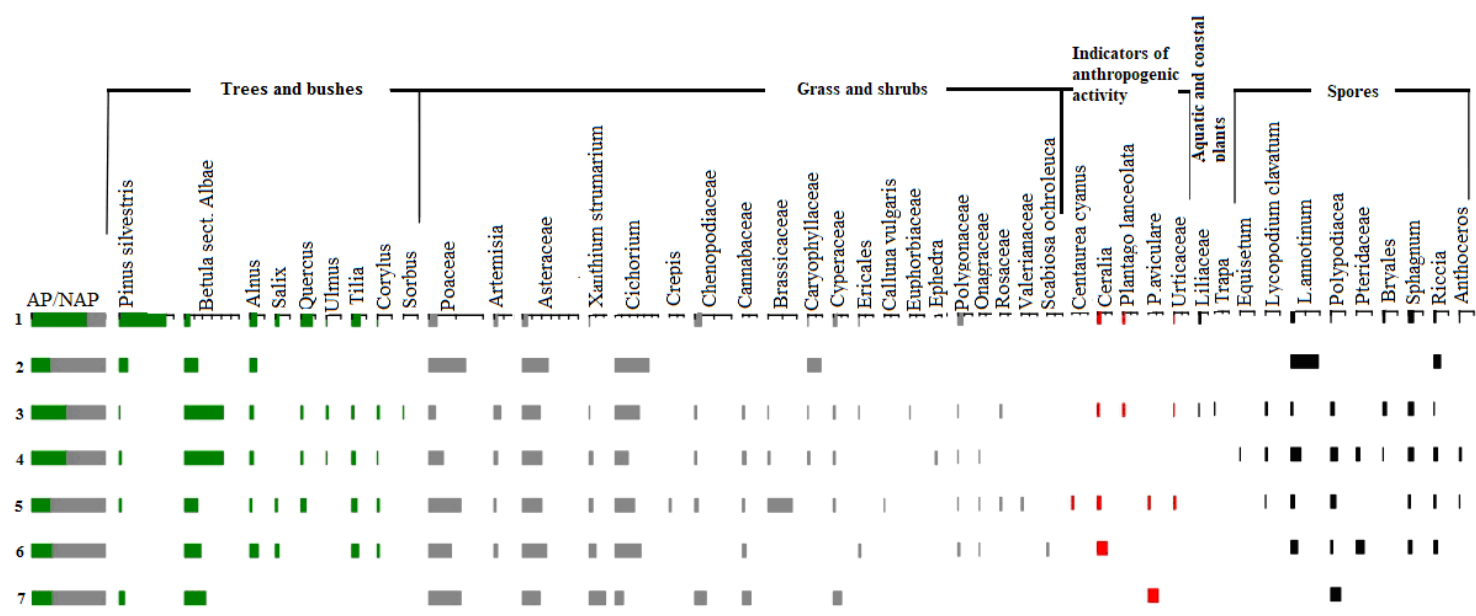

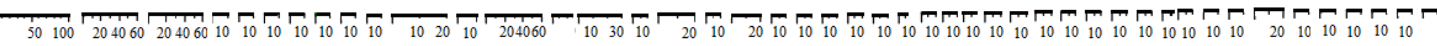

Figure 5. Soils spore-pollen diagram. 1- surface soil (1f-19), 2 - buried soil (3b-19), 3 - buried soil (2b-19 (1)), 4 - buried soil (2b-19 (2)), 5 - buried soil (4b-19), 6 - buried soil (5b-19 (1)), 7 - buried soil (5b-19 (2)). 
Pollen spectra from paleosols have quite significant differences both from the surface soil and from each other. The results of the palynological analysis revealed that the common difference between the spectra from buried soils from the surface soil is a significantly smaller proportion of pollen from woody plants (from 26.1 to $49.4 \%$ versus $75.9 \%$ ). Birch pollen, a pioneer plant in secondary forests, predominant in the spectra of buried soils. Birch populates areas of clear-cutting, conflagration; actively displaces pine and broadleaved plants due to high competitiveness [7].

In addition, in all samples from buried soils, a large number of coal microparticles were recorded, as well as the presence of spores of the Gelasinospora fungi from the order Sordariales - an indicator of fires. In the grassy part of the spectra there is dominance of pollen from plants of arid steppes and field weeds, which indicates a significant agrogenic load on the landscapes and, possibly, a greater warming and xerophytization, which is also indicated by the presence of Ephedra, Euphorbiaceae, Cannabaceae pollen in the spectra. In general, the composition of the spectra is characteristic of the forest-steppe with sections of birch forests, meadow communities, and a significant proportion of plowed territories.

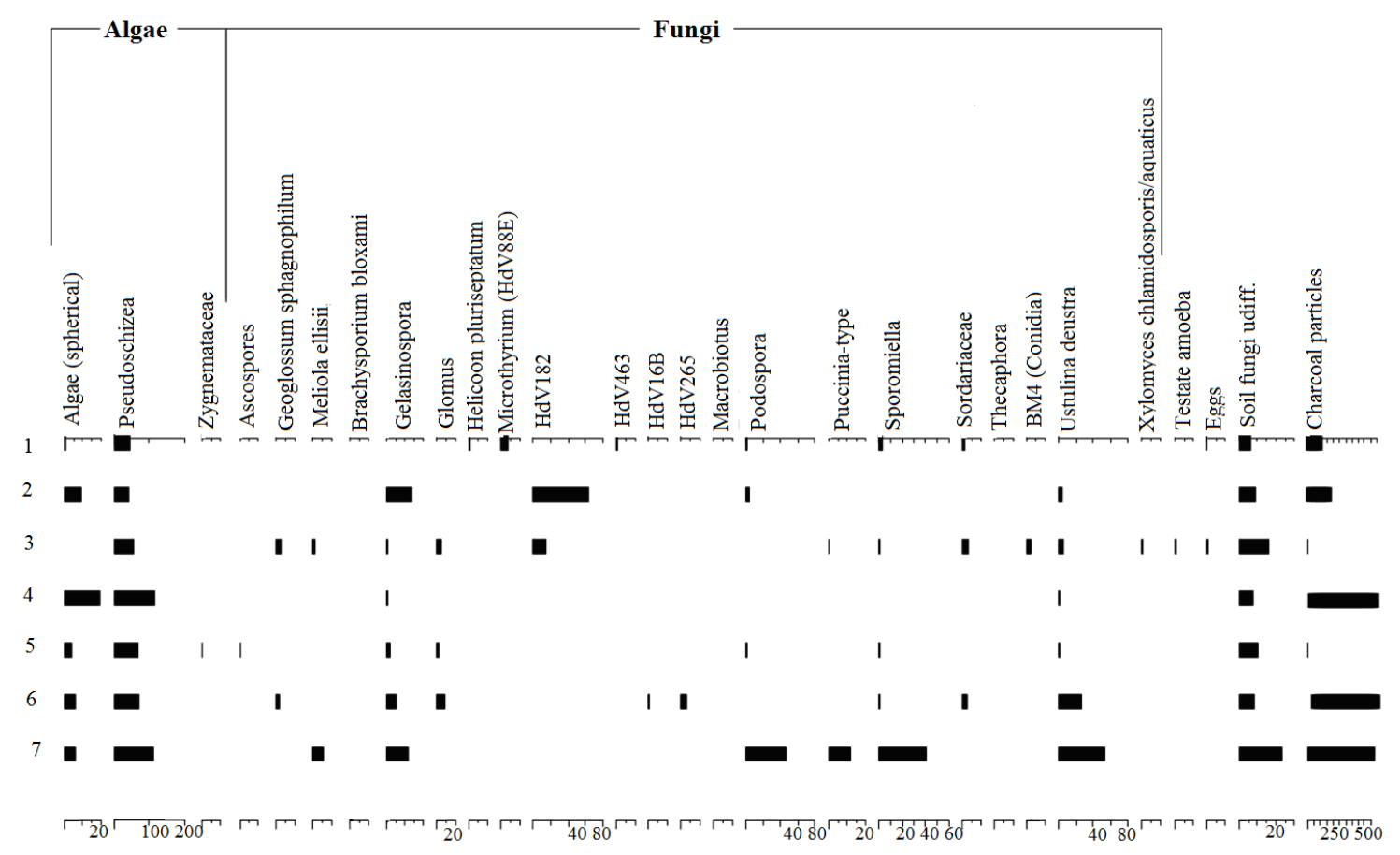

Figure 6. Diagram of non-pollen palynomorphs. 1- surface soil (1f-19), 2 - buried soil (3b-19), 3 - buried soil (2b-19 (1)), 4 - buried soil (2b-19 (2)), 5 - buried soil (4b-19), 6 - buried soil (5b-19 (1)), 7 - buried soil (5b-19 (2)).

In the palynospectrum from the soil, buried under the mound № 86 and dating from the 2nd half of the 11th century (2b-19), the pollen of birch dominates (more than $40 \%$ ), which may indicate the presence of a birch-oak forest at the moment of the burial. In the pollen spectrum from 3b-19 sample, the pollen of herbaceous plants accounts for more than $72 \%$, of which almost $50 \%$ is pollen of Asteraceae and chicory, which indicates the presence of open space: at the time of the construction of the mound, this was a plot of steppe or arable land. In the 5b-19 sample, the maximum content of Cannabaceae pollen was recorded, which can be interpreted as a signal of hemp cultivation in the region, which is confirmed by pollen data from neighbouring sections [7]. In the same sample, 
there are especially many spores of the fungus Ustulina deusta, which parasitizes on decaying dead wood.

The group of non-pollen palynomorphs is poorly diverse in composition - only soil algae Pseudoschizea are abundant, as well as spores of the coprotrophic fungi Sporomiella and Sordaria, which may indicate the proximity of the pasture zone (Fig. 6).

\section{CONCLUSIONS}

Buried soils vary in the depth of penetration of the quartz grains (siltans), which is the main feature for the studied soils, which can be used to judge the climatic differences during the burial. The most "humid" soil in the short chronological series of is the soil buried under mound barrow № 86 (2b-19), and the least moistened profile under barrow № 121 (3b-19). Apparently, climatic fluctuations for such a short period of time as 25 and 50 years led to a small transformation of the already formed, well-differentiated soil profile, however, similar topographic conditions, the formation of all soils on the same loess material, and the location on the territory of one forest massif allows us to consider the climate as the main variable characteristic. Since the soils buried under the mounds and the surface soil have a similar "forest" appearance, it can be assumed that before the construction of the mounds in the Middle Ages there was a clear cutting of the forest.

\section{Funding}

This research was funded by the Russian Science Foundation, № 19-18-00327.

\section{REFERENCES}

[1] Borisenkov E.P., Pasecki V.M. Extreme natural phenomena in Russian chronicles of the XIXVII centuries, Russia, 1983, 241 p. [In Russian];

[2] Kupriyanova L.A. Earring palynology, Science, Russia, 1965, 213 p. [In Russian];

[3] Kupriyanova L.A., Aleshina L.A. Pollen and spores of plants of the USSR flora. T. 1. Nauka, Russia, 1972, 171 p. [In Russian];

[4] Paleopalynology / Ed. Pokrovskaya, Vol. 1-3, Nedra, Russia, 1966, 24 p. [In Russian];

[5] Grimm, E.C. TILIAGRAPH vl.25 (computer software). Illinois State Museum, Research and Collections Center, Springfield, IL, USA, 1991, 25 p.;

[6] Grimm, E.C. TGView 2.0.2 (Software), Illinois State Museum, Research and Collections Center, Springfield, USA, 2004;

[7] Klimenko V.V., Klimanov V.A., Sirin A.A., Sleptsov A.M. Climate change in the western European part of Russia in the Late Holocene, Reports of the Academy of Sciences, Vol. 376, No. 5, Russia, 2001, pp. 679-683.

[8] Puzanova T.A., Aseeva E.N., Lebedeva M.P., Kurbanova F.G., Chernov T. The methods of research of buried soils under archaeological sites, International Multidisciplinary Scientific GeoConference Surveying Geology and Mining Ecology Management, SGEM, vol. 16, Bulgaria, 2018, pp. 611-619 